\title{
Detection of a large genomic deletion in the pancreatic secretory trypsin inhibitor (SPINK1) gene
}

\author{
Emmanuelle Masson ${ }^{1,2}$, Cédric Le Maréchal ${ }^{1,2,3}$, Jian-Min Chen ${ }^{1,2,4}$, Thierry Frebourg ${ }^{5}$, \\ Eric Lerebours ${ }^{6}$ and Claude Férec ${ }^{*}, 1,2,3,4$
}

\begin{abstract}
${ }^{1}$ INSERM, U613, 29220 Brest, France; ${ }^{2}$ Faculté de Médecine de Brest et des Sciences de la Santé, Université de Bretagne Occidentale, Brest, France; ${ }^{3}$ Laboratoire de Génétique Moléculaire et d'Histocompatibilité, CHRU Brest, Hôpital Morvan, Brest, France; ${ }^{4}$ Etablissement Français du Sang - Bretagne, Brest, France; ${ }^{5}$ Department of Genetics, Rouen University Hospital, Inserm U614, Faculty of Medicine, Rouen, France; ${ }^{6}$ Department of Hepatogastroenterology, Rouen University Hospital, Rouen, France
\end{abstract}

Mutations and polymorphisms in the SPINK1 gene, which encodes trypsin's physiological inhibitor, pancreatic secretory trypsin inhibitor, have been found to be associated with chronic pancreatitis. However, to date, all currently reported SPINK1 variants are either single-nucleotide substitutions or microinsertions/deletions. It is possible that large genomic rearrangements at this locus may underlie certain cases of chronic pancreatitis. However, such events, if indeed they exist, may have been overlooked by conventional PCR-based techniques. Here we attempted to screen all four exons as well as the promoter region of the SPINK1 gene for large genomic deletions by means of quantitative high-performance liquid chromatography analysis. Of the 47 pancreatitis families (not carrying any known PRSS1, SPINK1 and CFTR variants/mutations after screening the coding regions by our previously established denaturing highperformance liquid chromatography methods), one family was suggested to carry a large genomic deletion in the SPINK1 gene. The aberrant chromosomal junction was encapsulated by long-range PCR and the breakpoints were determined by direct sequencing of the rearranged fragment. A 2-bp short direct repeat was present at the deletion breakpoints; this simple deletion (c.1-320_c.55+961del1336 bp) can thus in principle be explained by replication slippage. Identification of this lesion has not only expanded the SPINK1 mutational spectrum but also served to identify a novel mutational mechanism causing chronic pancreatitis.

European Journal of Human Genetics (2006) 14, 1204-1208. doi:10.1038/sj.ejhg.5201684; published online 5 July 2006

Keywords: chronic pancreatitis; DHPLC; gross genomic deletion; pancreatic secretory trypsin inhibitor; quantitative high-performance liquid chromatography; SPINK1

Introduction

Pancreatitis is a continuing or relapsing inflammatory disease of the pancreas. More than a century ago, it was

*Correspondence: Professor C Férec, INSERM, U613, Université de Bretagne Occidentale, Etablissement Français du Sang - Bretagne, 46 rue Félix Le Dantec, Brest 29220, France. Tel: + 332 98445064;

Fax: + 332 98430555; E-mail: claude.ferec@univ-brest.fr

Received 28 April 2006; revised 29 May 2006; accepted 30 May 2006; published online 5 July 2006 proposed that pancreatitis is an autodigestive disease, and thereafter a wealth of circumstantial evidence, including clinical observations and experimental models, has suggested that prematurely activated trypsin is pivotal in initiating pancreatic autodigestion (reviewed by Chen and Férec $\left.^{1}\right)$. This theory was given wide support when an apparent 'gain-of-function' mutation, namely R122H, in the cationic trypsinogen gene (PRSS1; MIM \#276000), was identified as the cause of hereditary pancreatitis. ${ }^{2}$ 
Subsequently identified and functionally characterised pancreatitis-associated PRSS1 missense mutations including D19A, ${ }^{3} \mathrm{D} 22 \mathrm{G},{ }^{3,4} \mathrm{~K} 23 \mathrm{R},{ }^{3,4} \mathrm{~N} 29 \mathrm{I} / \mathrm{T},{ }^{5} \mathrm{E}^{3} 9 \mathrm{~K}^{6}$ and $\mathrm{R} 122 \mathrm{C}^{7}$ were also demonstrated to cause a 'gain' of trypsin. By contrast, 'loss-of-function' PRSS1 mutations ${ }^{8}$ as well as a degradation-sensitive anionic trypsinogen (PRSS2; MIM \#601564) variant (G191R) ${ }^{9}$ appear to protect against the disease.

Mutations and polymorphisms in the SPINK1 gene (MIM \#167790; encoding trypsin's physiological inhibitor, pancreatic secretory trypsin inhibitor) have also been identified and shown to be associated with chronic pancreatitis. ${ }^{10-12}$ However, to date, all currently reported SPINK1 variants $(\sim 30)$ are either single-nucleotide substitutions or microinsertions/deletions (see http://www.uni-leipzig.de/pancreasmutation/db.html for an up-to-date list). It is possible that large genomic rearrangements at this locus may underlie certain cases of chronic pancreatitis. However, such events, if indeed they exist, may have been overlooked by conventional PCR-based techniques.

We have recently reported that gross genomic rearrangements in the CFTR gene (MIM \#602421) accounted for a significant fraction of unidentified cystic fibrosis chromosomes by means of the quantitative multiplex PCR of short fluorescent fragments and quantitative high-performance liquid chromatography (QHPLC) analyses. ${ }^{13,14}$ In the present study, we have attempted to identify this kind of mutation in the SPINK1 gene using the QHPLC technique.

\section{Materials and methods}

\section{Pancreatitis families and controls}

A total of 47 unrelated pancreatitis families were recruited from several clinical centres in France. As described previously, ${ }^{15}$ all families were defined as having at least two cases of recurrent acute pancreatitis or chronic pancreatitis from whom known precipitating factors such as alcohol abuse and gallstones were excluded. In addition, these families had not been found to carry any known PRSS1, SPINK1 and CFTR variants/mutations after screening the coding regions by our previously established denaturing high-performance liquid chromatography technique. ${ }^{15-17}$ Fifty unrelated healthy bone marrow donors were used as controls.

\section{QHPLC analysis}

Primers used for amplifying the four exons of the SPINK1 gene were described elsewhere. ${ }^{15} \mathrm{~A}$ new primer pair (forward: 5'-GAAACTCTTTGCAGGAAATGCAG-3'; reverse: 5'-TCAAGCCCAAACCTCGTTGT-3') was further designated to amplify a fragment $(208 \mathrm{bp})$ corresponding to the promoter region of the gene. DNA quantification was performed using the Quant-iT ${ }^{\mathrm{TM}}$ PicoGreen ${ }^{\circledR}$ dsDNA reagent (Invitrogen, Eugene, OR, USA). PCR was performed in a $50 \mu \mathrm{l}$ reaction mixture containing of $200 \mu \mathrm{M}$ each dNTP,
1.5-2.5 mM $\mathrm{MgCl}_{2}, 1 \mathrm{U}$ AmpliTaq DNA polymerase (PE Applied Biosystems, Foster City, CA, USA), $0.5 \mu \mathrm{M}$ each primer and $100 \mathrm{ng}$ genomic DNA. The PCR programme consisted of an initial denaturation at $94^{\circ} \mathrm{C}$ for $2 \mathrm{~min}$, followed by $26-32$ cycles denaturation at $94^{\circ} \mathrm{C}$ for $30 \mathrm{~s}$, annealing at $50-60^{\circ} \mathrm{C}$ for $30 \mathrm{~s}$ and extension at $72^{\circ} \mathrm{C}$ for $30 \mathrm{~s}$.

QHPLC was performed using the Transgenomic Wave system. Briefly, $8 \mu \mathrm{l}$ PCR products were injected into a DNASep column $(50 \times 4.6 \mathrm{~mm})$ in nondenaturing condition $\left(50^{\circ} \mathrm{C}\right)$. All five amplicons were eluted in a linear acetonitrile gradient (54-64\% B buffer increased) with a $0.9 \mathrm{ml} \mathrm{min}^{-1}$ flow rate. Elution of DNA was detected by UV absorbance at $260 \mathrm{~nm}$ and data were visualised with Hitachi System Manager software. The presence of a deletion was indicated by a two-fold reduction in the height of the corresponding peak as compared with that of the control.

\section{Characterisation of the gross genomic deletion}

Expand Long Template PCR System (Roche Diagnostics, Meylan, France) was used to obtain the fragment spanning the aberrant chromosomal junction. The forward primer initially used for amplifying the promoter region and the reverse primer initially used for amplifying exon 2 of the SPINK1 gene were used as the forward and reverse primers of the long-range PCR, respectively. After 2 min denaturation at $94^{\circ} \mathrm{C}$, the PCR programme was 40 cycles of denaturation at $94^{\circ} \mathrm{C} \times 15 \mathrm{~s}$, annealing at $56^{\circ} \mathrm{C} \times 30 \mathrm{~s}$ and extension at $68^{\circ} \mathrm{C} \times 6 \mathrm{~min}$.

Long-range PCR products were visualised on a $1.4 \%$ agarose gel. The newly generated patient-specific band was purified on TaKaRa RECOCHIP (Takara Bio Inc., Otsu, Shiga, Japan) and then directly sequenced using the ABI PRISM $^{\mathrm{TM}}$ BigDye $^{\mathrm{TM}}$ Terminator Cycle Sequencing Kit (PE Applied Biosystems, Foster City, CA, USA).

\section{Mutation nomenclature}

The sequence of the rearranged PCR products was compared with GenBank accession numbers NM_003122.2. and NC_000005.8. The characterised gross deletion was named in accordance with the standard nomenclature guidelines proposed by the Human Genome Variation Society (http://www.hgvs.org/; i.e. cDNA-based numbering with the A of the ATG translational initiation codon as $+1) .^{18}$

\section{Results and discussion}

Taking advantage of our previous experience of QHPLC analysis of the CFTR gene, ${ }^{13,14}$ we have here established a similar method for systematically analysing the promoter region and all four exons of the SPINK1 gene. Of the 47 pancreatitis families analysed, one family was found to carry a large genomic deletion in the SPINK1 gene. The index patient in this family is a 47-year-old French woman, 
whose symptoms started at the age of 16 with severe abdominal pain. Chronic pancreatitis was diagnosed by the presence of calcifications in the pancreas and a dilated pancreatic duct, revealed by ultrasound and endoscopic retrograde cholangiopancreatography investigations. Eight of her 15 brothers and sisters were reported to have chronic pancreatitis. Her parents are healthy.

The index patient (II.1) as well as her 41-year-old brother with chronic pancreatitis (II.2) was suggested to carry a heterozygous deletion involving exon 1 of the SPINK 1 gene by QHPLC (Figure 1a). As the promoter region (data not shown) and exon 2 of the gene appeared to be normal in these two patients, this putative deletion's breakpoints should be located somewhere between the promoter region and exon 2 . We therefore used the forward primer initially used for amplifying the promoter region and the reverse primer initially used for amplifying exon 2 of the SPINK1 gene to perform a long-range PCR amplification. Indeed, an additional, shorter band was shown in the two patients as compared with a normal control (Figure 1b), thereby confirming the presence of a large deletion involving exon 1 in both patients. This shorter band was then recovered, purified and directly sequenced. As shown in Figure 1c and Figure 2, this deletion extends from nucleotide $-3205^{\prime}$ to the A of the ATG translational initiation codon to nucleotide $+9613^{\prime}$ to c.55 with a loss of $1336 \mathrm{bp}$ and was thus designated as c.1-320_c.55+961del1336bp (GenBank accession number DQ494480).

This large deletion was further detected in the index patient's 35-year-old brother with chronic pancreatitis
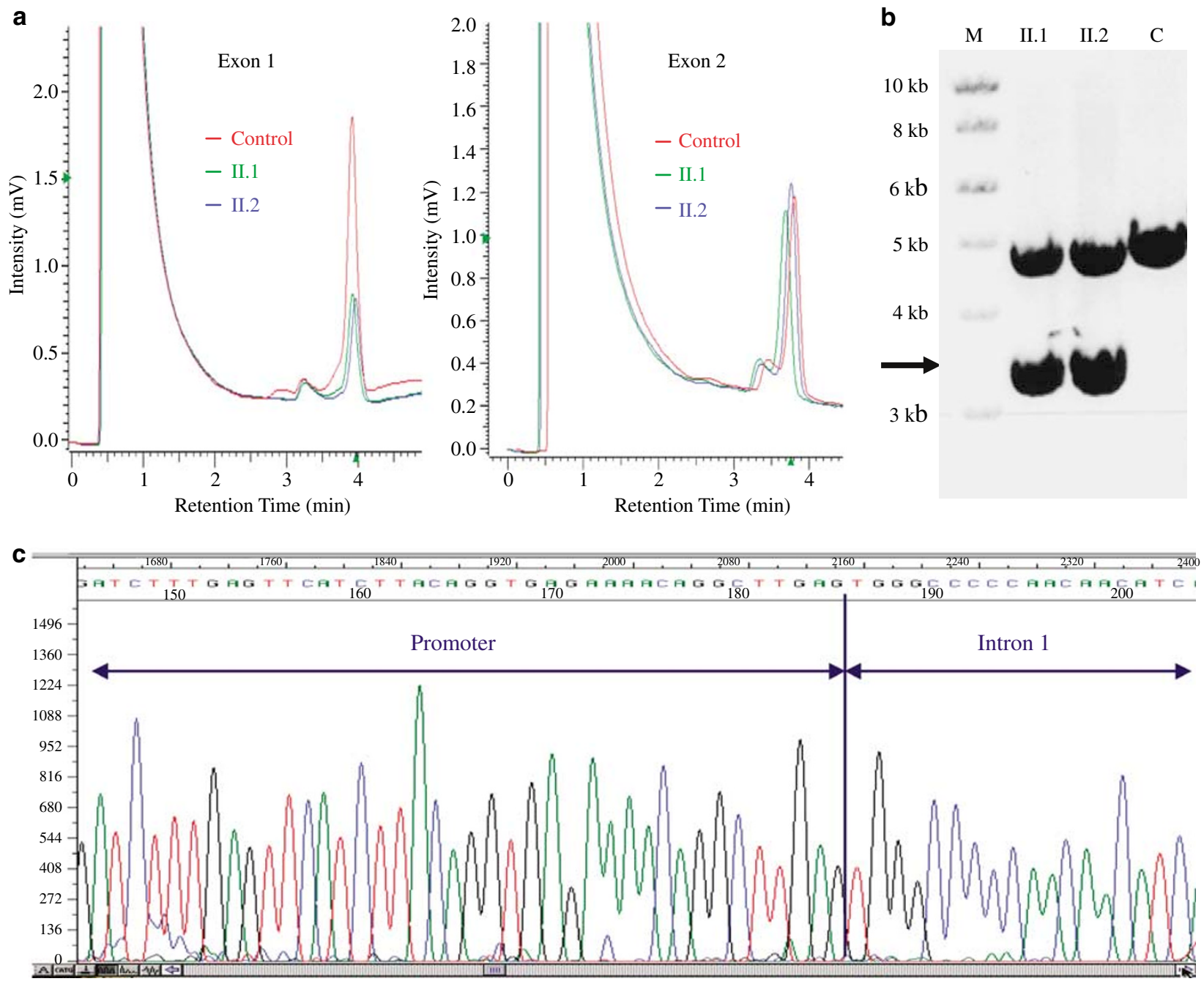

Figure 1 Characterisation of a large genomic deletion in the SPINK1 gene. (a) Superimposed QHPLC profiles of exons 1 and 2 from the index patient (II.1), one of her diseased brothers (II.2) and a normal control. (b) Electrophoretic profiles of the long-range PCR products from patients II.1 and II. 2 as well as a normal control (c) on a $1.4 \%$ agarose gel. Arrow indicates the newly generated, shorter band in the patients. M, SmartLadder ${ }^{\mathrm{TM}}$ marker (Eurogentec, Southampton, U K). (c) Determination of the chromosomal junction (indicated by a vertical bar) by direct sequencing. 


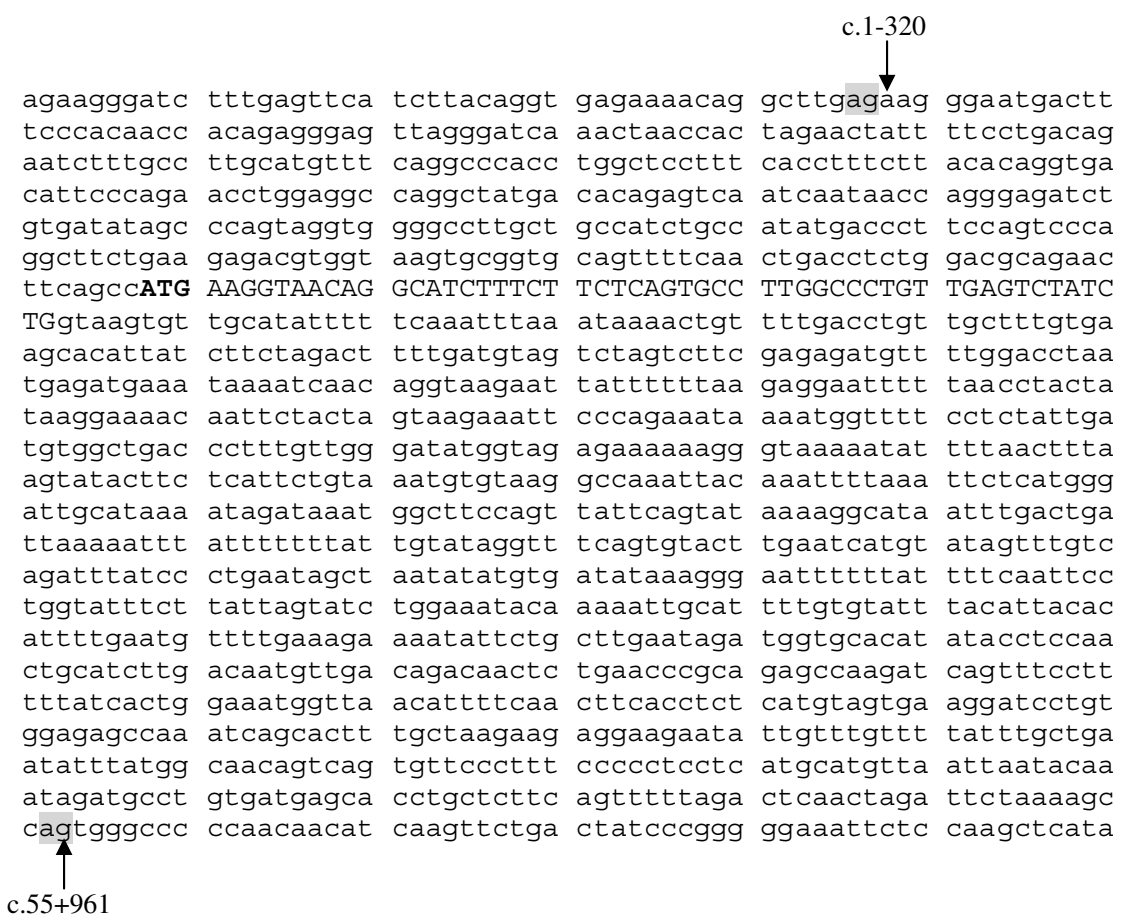

Figure 2 Illustration of the detected large genomic deletion in the SPINK1 gene. Coding sequence of exon 1 is in upper case and the translational initiation codon ATG is in bold. The start and end points of the deletion are indicated by arrows. The 2-bp direct repeat present at the $5^{\prime}$ and $3^{\prime}$ breakpoints are shaded. This large deletion, termed c.1-320_c.55 + 961del1336 bp, was deposited in GenBank (accession number DQ494480).

(data not shown). However, until now, we have been unable to obtain DNA samples from the patients' healthy parents and other family members for genetic analysis. In addition, this larger deletion was shown to be absent in 50 healthy controls by QHPLC analysis. Finally, a 2-bp short direct repeat (ag) was present at the deletion breakpoints (Figure 2); this deletion can thus in principle be explained by replication slippage. ${ }^{19}$

The newly identified large deletion as well as the previously reported c.2T $>\mathrm{C}^{11} \quad$ c. $194+2 \mathrm{~T}>\mathrm{C}$

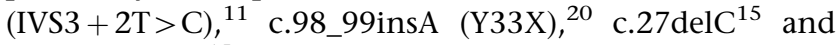
c. $87+1 \mathrm{G}>\mathrm{A} 1^{15}$ are severe mutations in the context of their presumed effect on SPINK1's function (i.e. complete functional loss of the involved allele). Not surprisingly, these mutations were always found in families with chronic pancreatitis. In sharp contrast, the most common N34S variant (and other intronic variants in linkage disequilibrium), which has an allele frequency of $0.18-$ $0.79 \%$ in control populations, ${ }^{10,11,12,21}$ was often found in sporadic pancreatitis. Based upon these observations, we would like to reiterate that the differing views (i.e. diseasecausing $^{11} v s$ disease modifier ${ }^{12}$ ) regarding SPINK1's role in the aetiology of chronic pancreatitis should be considered in the context of specific mutations: although the common N34S-associated haplotype is more like to act as a disease susceptibility factor, severe mutations are more likely to be disease-causing. ${ }^{15}$
In summary, we have reported the first large genomic deletion in the SPINK1 gene using a newly established QHPLC analysis. This finding has not only expanded the spectrum underlying SPINK1 mutations but also identified a novel mutational mechanism causing chronic pancreatitis. This kind of lesion should also be systematically searched for in other populations, by QHPLC or other techniques such as the multiplex ligation-dependent probe amplification. ${ }^{22}$

\section{Acknowledgements}

We are grateful to Professor David N Cooper (Cardiff, UK) for critically reading this manuscript. E Masson is a PhD student supported by the Programme Hospitalier de Recherche Clinique (Grant PHRC R 08-04 to $C F)$, France. JM Chen is a visiting Professor of Genetics supported by the Ministère de la Jeunesse, de l'Éducation Nationale et de la Recherche, France. This work was supported by the INSERM (Institut National de la Santé et de la Recherche Médicale).

\section{References}

1 Chen JM, Férec C: Molecular basis of hereditary pancreatitis. Eur J Hum Genet 2000; 8: 473-479.

2 Whitcomb DC, Gorry MC, Preston RA et al: Hereditary pancreatitis is caused by a mutation in the cationic trypsinogen gene. Nat Genet 1996; 14: 141-145.

3 Chen JM, Kukor Z, Le Marechal C et al: Evolution of trypsinogen activation peptides. Mol Biol Evol 2003; 20: 1767-1777. 
4 Teich N, Ockenga J, Hoffmeister A, Manns M, Mossner J, Keim V: Chronic pancreatitis associated with an activation peptide mutation that facilitates trypsin activation. Gastroenterology 2000; 119: $461-465$.

5 Sahin-Toth M: The pathobiochemistry of hereditary pancreatitis: studies on recombinant human cationic trypsinogen. Pancreatology 2001; 1: 461-465.

6 Teich N, Le Marechal C, Kukor Z et al: Interaction between trypsinogen isoforms in genetically determined pancreatitis: mutation E79K in cationic trypsin (PRSS1) causes increased transactivation of anionic trypsinogen (PRSS2). Hum Mutat 2004; 23: 22-31.

7 Simon P, Weiss FU, Sahin-Toth M et al: Hereditary pancreatitis caused by a novel PRSS1 mutation (Arg-122 $\rightarrow$ Cys) that alters autoactivation and autodegradation of cationic trypsinogen. J Biol Chem 2002; 277: 5404-5410.

8 Chen JM, Le Marechal C, Lucas D, Raguenes O, Ferec C: 'Loss of function' mutations in the cationic trypsinogen gene (PRSS1) may act as a protective factor against pancreatitis. Mol Genet Metab 2003; 79: 67-70.

9 Witt H, Sahin-Toth M, Landt $\mathrm{O}$ et al: A degradation-sensitive anionic trypsinogen (PRSS2) variant protects against chronic pancreatitis. Nat Genet 2006; 38: 668-673.

10 Chen JM, Mercier B, Audrezet MP, Ferec C: Mutational analysis of the human pancreatic secretory trypsin inhibitor (PSTI) gene in hereditary and sporadic chronic pancreatitis. I Med Genet 2000; 37: $67-69$.

11 Witt H, Luck W, Hennies HC et al: Mutations in the gene encoding the serine protease inhibitor, Kazal type 1 are associated with chronic pancreatitis. Nat Genet 2000; 25: 213-216.

12 Pfutzer RH, Barmada MM, Brunskill AP et al: SPINK1/PSTI polymorphisms act as disease modifiers in familial and idiopathic chronic pancreatitis. Gastroenterology 2000; 119: 615-623.

13 Audrezet MP, Chen JM, Raguenes O et al: Genomic rearrangements in the CFTR gene: extensive allelic heterogeneity and diverse mutational mechanisms. Hum Mutat 2004; 23: $343-357$.
14 Ferec C, Casals T, Chuzhanova N et al: Gross genomic rearrangements involving deletions in the CFTR gene: characterization of six new events from a large cohort of hitherto unidentified cystic fibrosis chromosomes and meta-analysis of the underlying mechanisms. Eur J Hum Genet 2006; 14: 567-576.

15 Le Marechal C, Chen JM, Le Gall C et al: Two novel severe mutations in the pancreatic secretory trypsin inhibitor gene (SPINK1) cause familial and/or hereditary pancreatitis. Hum Mutat 2004; 23: 205.

16 Le Marechal C, Bretagne JF, Raguenes O, Quere I, Chen JM, Ferec $\mathrm{C}$ : Identification of a novel pancreatitis-associated missense mutation, R116C, in the human cationic trypsinogen gene (PRSS1). Mol Genet Metab 2001; 74: 342-344.

17 Le Marechal C, Audrezet MP, Quere I, Raguenes O, Langonne S, Ferec C: Complete and rapid scanning of the cystic fibrosis transmembrane conductance regulator (CFTR) gene by denaturing high-performance liquid chromatography (D-HPLC): major implications for genetic counselling. Hum Genet 2001; 108 : 290-298.

18 den Dunnen JT, Antonarakis SE: Nomenclature for the description of human sequence variations. Hum Genet 2001; 109: 121-124.

19 Chen JM, Chuzhanova N, Stenson PD, Ferec C, Cooper DN: Metaanalysis of gross insertions causing human genetic disease: novel mutational mechanisms and the role of replication slippage. Hum Mutat 2005; 25: 207-221.

20 Gaia E, Salacone P, Gallo $\mathrm{M}$ et al: Germline mutations in CFTR and PSTI genes in chronic pancreatitis patients. Dig Dis Sci 2002; 47: $2416-2421$.

21 Chen JM, Mercier B, Audrezet MP, Raguenes O, Quere I, Ferec C: Mutations of the pancreatic secretory trypsin inhibitor (PSTI) gene in idiopathic chronic pancreatitis. Gastroenterology 2001; 120: $1061-1064$

22 Kriek M, White SJ, Szuhai K et al: Copy number variation in regions flanked (or unflanked) by duplicons among patients with developmental delay and/or congenital malformations; detection of reciprocal and partial Williams-Beuren duplications. Eur J Hum Genet 2006; 14: 180-189. 